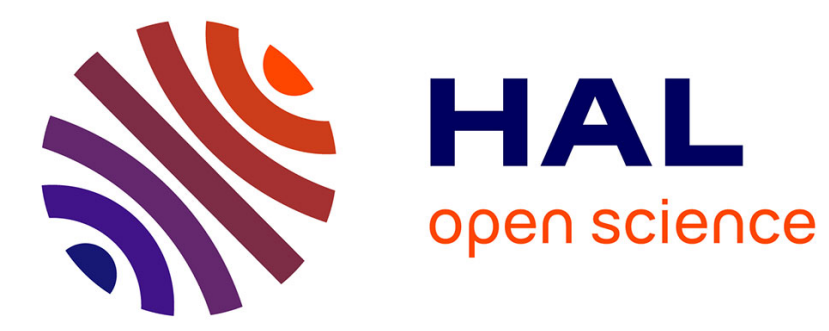

\title{
Reconsidering the Impact of National Soccer Results on the FTSE 100
}

\author{
Christian Klein, Bernhard Zwergel, Henning John Fock
}

\section{To cite this version:}

Christian Klein, Bernhard Zwergel, Henning John Fock. Reconsidering the Impact of National Soccer Results on the FTSE 100. Applied Economics, 2009, 41 (25), pp.3287-3294. 10.1080/00036840802112471. hal-00582283

\section{HAL Id: hal-00582283 \\ https://hal.science/hal-00582283}

Submitted on 1 Apr 2011

HAL is a multi-disciplinary open access archive for the deposit and dissemination of scientific research documents, whether they are published or not. The documents may come from teaching and research institutions in France or abroad, or from public or private research centers.
L'archive ouverte pluridisciplinaire HAL, est destinée au dépôt et à la diffusion de documents scientifiques de niveau recherche, publiés ou non, émanant des établissements d'enseignement et de recherche français ou étrangers, des laboratoires publics ou privés. 


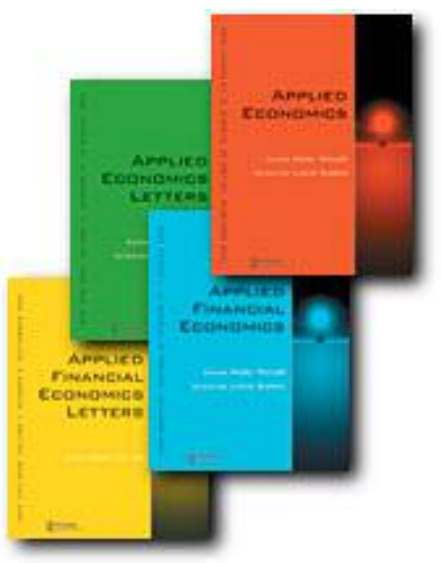

Reconsidering the Impact of National Soccer Results on the FTSE 100

\begin{tabular}{|r|l|}
\hline Journal: & Applied Economics \\
\hline Manuscript ID: & APE-07-0738.R1 \\
\hline Journal Selection: & Applied Economics \\
\hline Date Submitted by the & 22-Mar-2008 \\
\hline Complete List of Authors: & $\begin{array}{l}\text { Klein, Christian; University of Hohenheim, 510 C Chair of Finance } \\
\text { and Accounting } \\
\text { Zwergel, Bernhard; University of Augsburg, Chair of Statistics } \\
\text { Fock, Henning; University of Augsburg, Chair of Banking and } \\
\text { Finance }\end{array}$ \\
\hline JEL Code: & $\begin{array}{l}\text { G10 - General < G1 - General Financial Markets < G - Financial } \\
\text { Economics, G12 - Asset Pricing < G1 - General Financial Markets < } \\
\text { Efficiency|Event Studies < G1 - General Financial Markets < G - } \\
\text { Financial Economics }\end{array}$ \\
\hline Keywords: & $\begin{array}{l}\text { Sentiment, Replication Studies, Event Studies, Data Mining, Market } \\
\text { Efficiency }\end{array}$ \\
\hline
\end{tabular}

\section{๑scholaroNE" \\ Manuscript Central}




\section{Reconsidering the Impact of National Soccer Results on the FTSE 100}

Christian Klein $^{\mathrm{a}}$, Bernhard Zwergel ${ }^{\mathrm{b}}$ and J. Henning Fock ${ }^{\mathrm{c}}$

\section{Running Title: Reconsidering the Impact of National Soccer Results on the}

FTSE 100

In past decades, many empirical studies revealed return anomalies in many different asset classes and markets. Very recent publications have, however, even found evidence that stock markets react to the results of soccer matches.

In this paper, we argue that such empirical studies should be analyzed carefully; we thus endorse the use of replication studies to verify results. Consequently, by rebuilding the study of Ashton et al. (2003), we are able to detect mistakes in the empirical set-up. Based on these findings, we demonstrate how even minor flaws can have a crucial influence on the results of such studies and point out pitfalls that are frequently encountered. We furthermore emphasize the importance of robustness checks to validate the results of empirical studies.

\footnotetext{
${ }^{a}$ Corresponding author, Chair of Accounting and Financing, University of Hohenheim, Schloß Osthof Ost, 70593 Stuttgart, Germany, Tel.: (+49)711/459-22657,

E-Mail: cklein@uni-hohenheim.de

${ }^{b}$ Chair of Statistics, University of Augsburg, Germany,

E-Mail: bernhard.zwergel@wiwi.uni-augsburg.de

${ }^{c}$ Chair of Banking and Finance, University of Augsburg, Germany,

E-Mail: john.henning.fock@wiwi.uni-augsburg.de
} 


\section{Reconsidering the Impact of National Soccer Results on the FTSE 100}

\section{Running Title: Reconsidering the Impact of National Soccer Results on the FTSE 100}

In past decades, many empirical studies revealed return anomalies in many different asset classes and markets. Very recent publications have, however, even found evidence that stock markets react to the results of soccer matches.

In this paper, we argue that such empirical studies should be analyzed carefully; we thus endorse the use of replication studies to verify results. Consequently, by rebuilding the study of Ashton et al. (2003), we are able to detect mistakes in the empirical set-up. Based on these findings, we demonstrate how even minor flaws can have a crucial influence on the results of such studies and point out pitfalls that are frequently encountered. We furthermore emphasize the importance of robustness checks to validate the results of empirical studies. 


\section{Introduction}

In recent years, empirical researchers have put much effort into uncovering stock market anomalies. The results often violate the traditional efficient market hypothesis and sometimes result in the mistrust of traditional asset-pricing models. Today, we believe that many irrational aspects do indeed play a role in the formation of returns: daily stock returns are, for example, correlated with sunshine (see Hirshleifer and Shumway, 2003), daylight saving changes (see Kamstra et al., 2000), and sporting events. Edmans et al. (2007) demonstrate a significant relation between soccer match results and stock returns. They also document a loss effect after other international sports events like cricket, rugby, and basketball games. The authors argue that the literature on psychology indicates that sport results have a significant effect on investors' mood in general.

In their study on the influence that the performance of England's national soccer team has on the British FTSE 100 index, Ashton et al. (2003) find a statistically significant relationship. For these authors, the economic importance of sport events is the rationale for stock markets reacting to a soccer team's performance.

The "soccer industry" indubitably plays an important economic role. The World Cup 2006 in Germany exemplified this when approximately 4 million fans came from abroad to support their teams. FIFA (Fédération Internationale de Football Association), the international governing body of the soccer association, generated total revenues of CHF 2.858 billion ( $\$ 2.594$ billion) with this World Cup. Could this have had an impact on the stock market? Since FIFA is neither capital market oriented, nor listed, we assume that in terms of GDP, the role of the "soccer industry" is not a significant one at all. 
In terms of psychological factors, the assumption that the outcome of a soccer game does have an influence on the stock market the day following the match is very unlikely as well - however compelling the argument might look at first glance. This is exemplified, for example, by Germany's defeat by Italy in the 2006 World Cup semifinal. This was a shock for Germans (and, of course, for German shareholders); nevertheless, the World Cup event still had an overall positive effect on the German economy. Furthermore, a large portion of the German DAX free float is traded by foreign investors who were arguably not interested in the outcome of that game (they might even have been Italians!). Was there therefore a rationale for the DAX index to reflect the outcome of this game?

We replicated the study by Ashton et al. (2003) and were able to detect several inconsistencies in their event study set-up. Based on these findings, we present typical mistakes found in such empirical studies, especially in event studies, which are extremely susceptible to errors and assumptions. These errors should be avoided, as even small variances in the measuring of an event can influence the results strongly.

Our aim with this paper is to encourage the utilization of replication studies. ${ }^{1} \mathrm{We}$ want to stress the importance of publishing empirical papers that do not find statistically significant results (especially when studying topics related to market efficiency, see, e.g., Fama, 1970, 1991).

The outline of this paper is as follows: in the next section we demonstrate, by means of a replication study, that the original study by Ashton et al. (2003) contains several basic mistakes and could lead to quite different results. Section 3 applies robustness checks to the corrected results and the last section summarizes our findings and concludes the paper.

\footnotetext{
${ }^{1}$ On the importance of replication studies see Hubbard and Vetter (1996) 


\section{Replication of the Study by Ashton et al. (2003)}

In their empirical study, which covers the period January 6, 1984 to July 3, 2002, Ashton et al. (2003) find a strong link between the performance of England's national soccer team and daily changes on the London Stock Exchange's FTSE 100 index. The authors arrive at this finding after performing an event study analysis of the London Stock Exchange's stock index movements following international matches played by the national soccer team. In conclusion, they use a binomial test to check whether the return of the trading day following a soccer game differs from the unconditional mean return of all other trading days.

We rebuilt the above-mentioned study in respect of the same time period, with daily prices sourced from Datastream and soccer game results from various media. We subsequently arrived at results that differed from the ones reported by Ashton et al. (2003). In order to explain this divergence, we studied possible distortions in event studies in greater depth. By not correcting them, we were able to reproduce some of the results produced by Ashton et al. (2003). The differences between our (corrected) results and those of Asthon et al. (2003) are noteworthy.

\subsection{Holiday Return Effect}

Ashton et al. (2003) used Datastream as the source of their capital market data. Generally, the data quality is very good, but there is one problem: Datastream always reports the last price if there has been no trading on a holiday. This effect produces a zero return for every holiday within the data series, which can seriously distort an empirical investigation if this effect is not corrected. A possible solution is to use Datastream's holiday function, which shows a price of "\#NA" for holidays when the data file is downloaded. Another solution is to select all returns with a zero size and 
check them against a calendar, removing them if they fell on holidays. Checking against a calendar is crucial because it is also possible, although not very likely, that two real closing prices could be identical. The latter could occur since, for example, genuine zero returns were not all that uncommon in the early days of the FTSE 100 index when its level was not particularly high.

It is definitely a grave mistake not to correct zero returns in the data set. When using the data of final match days, we were closer to the results provided by Ashton et al. (2003) than when we did correct zero returns on holidays. This affected, for example, the data regarding the game played on Sunday, June 2, 2002 (World Cup, England vs. Sweden). The following two weekdays were public holidays: on June 3, the Queen's Golden Jubilee was celebrated and June 4 was the spring bank holiday. Ashton et al. (2003) apparently used a zero return to compute the abnormal return for this final game, as our results converged with theirs when we did the same. We thereafter checked other pitfalls and were able to replicate more of their results.

\subsection{The "Copy and Paste" Effect}

Ashton et al. (2003) report that within the study period, England's national soccer team participated in 35 "tournament final games" of which they won 12 games, lost 12, and drew 11. This information is not actually correct, but by accessing the national soccer team's official homepage and doing a "copy and paste" of the "fixtures and results," it was possible to replicate the above results. The correct distribution of the 35 "tournament finals games" was, however, 13 wins, 14 losses, and 8 draws. There is, however, a further problem: the list of games within the study period ends with a semi-final at Wembley Stadium on June 26, 1996, which resulted in a draw (1:1). This is, of course, not possible in a semi-final. The game was won 6:5 by Germany after a penalty shootout and indicated as such in the list by an 
asterisk, which could be overlooked when "copying and pasting." The impact on the results is, however, enormous. Since Ashton and his colleagues argue that there is a "feel-good factor," it should, in this case, have been quite low as the national team had lost a semi-final. However, it is quite obvious that all the errors made had a strong influence on the empirical analysis results.

\subsection{The Globalization Effect}

In every event study, the point in time is of extraordinary importance when measuring the event's impact on stock returns. Efficient markets will immediately reflect the effect of the event in the stock prices (MacKinlay, 1997). The London Stock Exchange does not trade around the clock; consequently, if the result of a soccer game is known before $4.30 \mathrm{pm}$ BST on the day, this result will be reflected in that day's closing price, otherwise in the next trading day's closing price. It is therefore important to identify the exact time of the event to group it accordingly. In their article, Ashton et al. (2003) mention that they always used the return of the trading day following the soccer game. In general, this procedure cannot be criticized, because the majority of soccer games in Europe (with only a few exceptions) are decided after stock exchange trading hours. An exception would be the World Cup 2002 hosted by Japan and South Korea. The time difference between the UK and Japan is +8 hours. During this World Cup, some kick-offs took place during the evening, which was around midday British time. Consequently, the results were known on the day of the soccer game and were already digested in the day's closing price. Any measurement of the effect of the match result on the next trading day would therefore distort the results. It is, however, possible to argue against our assertion. Without using market microstructure data, it is indeed difficult to assess the effects of these games in an entirely undistorted way. 


\subsection{The Correct(ed) Outcomes}

By including the aforementioned errors, we were able to replicate the results of Ashton et al. (2003) in respect of tournament final matches' draws and losses. These are presented in tables 1 and 2, while tables 3 and 4 reflect the new results after the distortions had been corrected.

As illustrated in table 1, Ashton et al. (2003) indicate that all games have a positive mean return after a win and a negative mean return after a defeat. When comparing these results with ours (table 3), the difference becomes evident. In our study, the mean returns after losses are considerably less negative or even positive. This effect is also evident with regard to wins, which become less positive. The results are even positive in games that end in a draw, with the exception of tournament finals.

We also tested the significance of our results and found that compared to the Ashton et al. (2003) study, the statistical significance had changed tremendously. In duplicating these authors' study, we used binomial statistics to test whether the expected return on the next day's ${ }^{2}$ trading was greater (or less) than the unconditional mean return after a win (or loss) by considering what proportion of returns after a particular game outcome exceeded the unconditional mean return. In the original study (table 2), all mean returns after a loss are significant on a 5\% or better level. In our study (table 4), only one result is significant on a 5\% significance level. We also find no significant results in respect of a win, as demonstrated in table 2.

It is important to note that in both studies significant results are not independent of one another: "tournament final games" are, of course, a subgroup of "tournament finals and qualifying games." Further, it is evident that the significant results of "tournament finals games" are the only reason why the larger sample is significant.

\footnotetext{
${ }^{2}$ Or the same trading day, depending on the time of the event.
} 
Ultimately, we could therefore not support Ashton and colleagues' conclusion that there is a "statistically significant relationship between the performance of the English national soccer team and the change in the price of shares traded on the London stock exchange" (Ashton et al., 2003, p. 785). The only appropriate significant results seem to be the stock market reactions after the English soccer team suffered losses in tournament finals. This result is astonishing insofar as we doubt that soccer fans are equipped with large short-selling capacities, since this instrument is not much used by private investors and was certainly not available some years ago.

$$
\begin{aligned}
& \text { [Insert Table } 1 \text { about here] } \\
& \text { [Insert Table } 2 \text { about here] } \\
& \text { [Insert Table } 3 \text { about here] } \\
& \text { [Insert Table } 4 \text { about here] }
\end{aligned}
$$

Another interesting finding is that even small variations or mistakes in the data set can have a huge impact on the results of an event study. After notifying Ashton and colleagues of our findings, they obtained almost the same results using the suggested corrections. However, there was still an asymmetry between the two studies concerning the time at which the return should be measured. In their study, the authors always use the next available trading day, whereas in our study, if the game results were known during stock exchange trading hours, that day was used rather than the following day. We therefore computed a mean return of $0.0186 \%$ in respect of the thirteen wins in tournament finals (see table 3), whereas Ashton et al. (2003) computed $0.1795 \%{ }^{3}$. We could then replicate their results by employing different returns in respect of two of the 13 matches - those held on June 7, 2002 and June 15, 1998.

\footnotetext{
${ }^{3}$ Ashton et al. provided us with the result of one game corrected in respect of the "copy and paste" effect.
} 
The first game (June 7, 2002) was the world championship in Sapporo, Japan where the English team defeated Argentina (1:0). Since, the kickoff was at 8:30 pm Japan time, the result was known during the London Stock Exchange trading hours on the day of the game (Friday at about $2.15 \mathrm{pm}$ GMT). We therefore took a return of $0.750964 \%$ to compute the average. Ashton et al. used the return of the following trading day $(0.158727 \%)$, which was a Monday, to compute their average. On the second date (June 15, 1998), the game in Marseille kicked-off at 2:30 pm local time on a Monday. Hence, the result was known at the London Stock Exchange that same day (approximately $3.15 \mathrm{pm})$. Consequently, we used that return $(-0.937641 \%)$. Ashton et al. (2003), however, used the return (0.244939\%) of the next day, Tuesday, to compute their average.

Which of the two standpoints is the correct one is not relevant in this case, but this example does indicate how sensitive, and therefore easy to influence, such results are, especially when sample sizes are very small.

\section{Robustness Checks}

In the following section, we address the problem of data mining that make robustness checks essential. We discuss a variety of possible robustness checks and, by means of the study by Ashton et al. (2003), demonstrate how formerly significant results disappear when robustness checks are applied.

Using large financial databanks makes research much easier for investigators. However, they also run the risk of finding significant correlations between variables that are no more than a statistical fluke. Moreover, it is known that papers with 
significant effects are much more likely to be published; an effect also known as the "file-drawer bias." 4

To avoid reporting significant but wholly spurious correlations, sophisticated researchers apply robustness checks to their results to counter the data-mining argument.

\subsection{Sub-Samples}

An easy way to check the robustness of empirical results is to divide the entire sample into sub-periods, Sub-period make it possible to check if the discovered correlations are stable over time. If they are not, there are two possible explanations:

1. For some reason, the correlation regime has changed over time. This may be due to structural changes, behavioral changes, or something else. Whatever the reason, the authors have to find a logical economic explanation for these changes.

2. The correlations are pure coincidence.

We divided the entire Ashton et al. (2003) sample into two sub-periods to check the robustness of the empirical results. The first sub-sample includes the period 1984 to 1993, the second the one 1994 to 2002. In the corrected results (table 4), a significant relationship is found between games lost and the FTSE returns on the following trading day.

Table 5 presents the results of this robustness check. There are (still) significant results in the first sub-sample: an English soccer team defeat produces a FTSE stock market return that is below the average FTSE return. Please note that "tournament finals games" is a sub-sample of "tournament finals and qualifying games" - the significant results of "tournament finals games" are the only reason why the larger sample is significant. In the second sub-sample (1994-2002), the significance does

\footnotetext{
${ }^{4}$ See McQueen et al. (1997), p. 69.
} 
not only disappear, the effect is also reversed: there are more days with a higher than average return after a game ending in defeat than days with a lower return. Since there is no logical explanation for this finding, we attribute the first sample's significant results to pure coincidence.

\section{[Insert Table 5 about here]}

\subsection{Outliers}

A common characteristic associated with financial time series like stock market series is the presence of extreme observations. Consequently, statistics derived from financial data sets include outliers and is often misleading. This is a real problem when computing OLS regressions or - like Ashton et al. (2003) did - calculating means. A common approach to check for the influence of outliers is to eliminate the extreme quantiles (e.g., the $1 \%$ quantiles) of the observations.

Table 6 is thus similar in structure to table 3, but the largest and smallest returns were eliminated when the average mean returns were computed. It becomes clear that the mean return after a victory in a final turns negative, which is contrary to Ashton et al.'s (2003) perception.

[Insert Table 6 about here]

\subsection{Confounding Events, Seasonal Effects, and Economic Relevance}

Additional robustness checks would be possible: We could check for confounding events, like ad-hoc announcements or changes in interest rates on the day of a soccer game. Furthermore, it might be logical to estimate and remove seasonal effects from the time series: discovered correlations may, after all, be attributable to business 
cycles or calendar anomalies. In addition, criticism in respect of data snooping could be avoided by studying out-of-sample data.

Finally, even if there were a relationship between soccer results and stock market outcomes, there is still one unanswered question: so what?

From a theoretical point of view, such a finding would challenge the efficient market hypothesis. We call financial markets "efficient" if they don't allow investors to earn above-average, risk-adjusted returns. From a practical point of view, investors could be interested in such a finding if this knowledge were to allow them to earn money. Whatever the case, empirical researchers would need to find a trading strategy in order to generate abnormal returns on the basis of a discovered anomaly. We doubt that this is possible, even if trading costs were not taken into account.

We do not see the necessity of doing additional checks on the Ashton et al. (2003) study. In our opinion, we have already supplied sufficient evidence that there is no link between England's national soccer team's achievements and the British FTSE 100 index.

\section{Conclusions}

The aim of this study was twofold. Primarily, we wanted to point out some errors in previous empirical studies. By means of a replication study, it was demonstrated that even small mistakes could have a strong influence on empirical studies results. Consequently, the importance of replication studies was illustrated.

In our opinion, replication studies have two predominant effects: first, they evaluate the set-up of the original empirical study and find possible mistakes - as we did in respect of the Ashton et al. (2003) paper. Second, by using new (independent) data, it 
is possible to rule out the occurrence of a statistical Type $\mathrm{I}^{5}$ error in the original empirical study. Marquering et al. (2006), for example, examined several wellknown stock market anomalies before and after publication. They demonstrate that most of the effects disappeared after publication, or may never have existed at all. The problem with these kinds of papers is that they culminate in non-significant results, which are rather difficult to have published.

In general, studies on market anomalies are always prone to the accusation of "data mining," i.e. searching for coincidently significant results in large data sets. If data sets are large enough and contain many variables, it is obvious that significant (although useless) interrelations can sometimes be found by sheer coincidence. This can be a problem, as "publication bias" (or the "file-drawer problem"), known from medical publications, also plays an important role in economics. Studies with significant results are therefore more likely to be published; conversely, studies without such results are not publishable and are ignored. However, the efficiency of capital markets can never be proven significantly, only their failure can. One can only hope that the reputation of replication studies, as well as studies without significant results will improve in future.

\footnotetext{
${ }^{5}$ See, e.g., Lindgren (1993), p. 308 for a description.
} 


\section{References:}

Ashton, J. K., Gerrard, B. and Hudson, R. S. (2003) Economic impact of national sporting success: evidence from the London stock exchange, Applied Economics Letters, 10, 783-785.

Edmans, A., Garcia, D. and Norli, Ø. (2007) Sports sentiment and stock returns, Journal of Finance, 62, 1967-1998.

Fama, E. F. (1970) Efficient capital markets: A review of theory and empirical work, Journal of Finance, 25, 383-417.

Fama, E. F. (1991) Efficient capital markets: II, Journal of Finance, 46, 1575-1617.

Hirshleifer, D. and Shumway T. G. (2003) Good day sunshine: Stock returns and the weather, The Journal of Finance, 58, 1009-1032.

Hubbard, R. and Vetter, D. E. (1996) An empirical comparison of published replication research in accounting, economics, finance, management, and marketing, Journal of Business Research, 35, 153-164.

Kamstra, M. J., Kramer, L. A. and Levi, M. D. (2000) Losing sleep at the market: The daylight saving anomaly, American Economic Review, 90, 1005-1011.

Lindgren, B. W. (1993) Statistical theory, Chapman and Hall, New York, USA. 
MacKinlay, A. C. (1997) Event studies in economics and finance, Journal of Economic Literature, 35, 13-39.

Marquering, W., Nisser, J. and Valla, T. (2006) Disappearing anomalies: a dynamic analysis of the persistence of anomalies, Applied Financial Economics, 16, 291-302.

McQueen, G., Shields, K. and Thorley, S. R. (1997) Does the "Dow-10 Investment Strategy" beat the Dow statistically and economically?, Financial Analysts Journal, 53, 66-72. 
Table 1

Descriptive Statistics (Ashton et al., 2003)

\begin{tabular}{lllll}
\hline & Number of games & $\begin{array}{l}\text { Mean return after win } \\
\text { (No. of wins) }\end{array}$ & $\begin{array}{l}\text { Mean return after } \\
\text { draw (No. of draws) }\end{array}$ & $\begin{array}{l}\text { Mean return after loss } \\
\text { (No. of losses) }\end{array}$ \\
\hline $\begin{array}{l}\text { The FTSE 100 index: Period of Investigation 6 January 1984-3 July 2002 } \\
\text { Unconditional Daily Return on the index 0.03511\% }\end{array}$ & & \\
\hline $\begin{array}{l}\text { All internationals } \\
\text { Tournament finals and } \\
\text { qualifying games }\end{array}$ & 210 & $0.1705 \%(102)$ & $-0.000481 \%(70)$ & $-0.1289 \%(38)$ \\
Tournament finals games & 35 & $0.3085 \%(49)$ & $-0.1843 \%(33)$ & $-0.1863 \%(17)$ \\
\hline
\end{tabular}

The table shows the results of Ashton et al. (2003). "Tournament finals games" are all games of international tournaments of the English national soccer team. For "Tournament finals and qualifying games" qualifying competitions for

major international tournament are added. "All internationals" include all types of international soccer games of the English national soccer team, including non-tournament 'friendly' matches.

Ashton et al compute positive mean returns of the FTSE 100 index after wins and negative mean returns after losses. 
Table 2

Binomial Statistics (Ashton et al., 2003)

\begin{tabular}{|c|c|c|}
\hline & No. of games played & $\begin{array}{l}\text { No. of returns after a win/loss which are }>/ \leq \text { the } \\
\text { unconditional mean. (Total no. of wins/losses) }\end{array}$ \\
\hline & & Loss \\
\hline All internationals & 210 & $27 * * *(38)$ \\
\hline $\begin{array}{l}\text { Tournament finals and } \\
\text { qualifying games }\end{array}$ & 99 & $13 * *(17)$ \\
\hline Tournament finals games & 35 & $9 * *(11)$ \\
\hline
\end{tabular}

This table presents the binomial statistics of Ashton et al. (2003). The intuition in column "win" is that the average return for the index after a win is greater than the unconditional mean return. The number in brackets is the number of won games of the English team, the number without brackets is the amount of cases where the average return for the index after a win is greater than the unconditional mean return.

In column "loss" they test whether the average return for the FTSE 100 index after a loss of the national soccer team is significantly less than the unconditional mean return for all types of matches.

For instance, the English soccer team has lost 38 games, the FTSE 100 index has fallen by an amount greater than the unconditional mean return on 27 of these occasions.

$*, * *, * * *$ indicates significance at the $10 \%, 5 \%$ and $1 \%$ level, resp. 
Table 3

Descriptive Statistics (corrected)

\begin{tabular}{lllll}
\hline & Number of games & $\begin{array}{l}\text { Mean return after win } \\
\text { (No. of wins) }\end{array}$ & $\begin{array}{l}\text { Mean return after } \\
\text { draw (No. of draws) }\end{array}$ & $\begin{array}{l}\text { Mean return after loss } \\
\text { (No. of losses) }\end{array}$ \\
\hline $\begin{array}{l}\text { The FTSE 100 index: Period of Investigation 6 January 1984-3 July 2002 } \\
\text { Unconditional Daily Return on the index 0.03655\% }\end{array}$ & & & \\
\hline $\begin{array}{l}\text { All internationals } \\
\text { Tournament finals and } \\
\text { qualifying games }\end{array}$ & 210 & $0.1126 \%(103)$ & $0.0512 \%(65)$ & $0.0069 \%(42)$ \\
Tournament finals games & 35 & $0.1424 \%(48)$ & $0.1634 \%(29)$ & $-0.0420 \%(20)$ \\
\end{tabular}

The table shows our corrected the results and is organized like table 1. "Tournament finals games" are all games of international tournaments of the English national soccer team. For "Tournament finals and qualifying games" qualifying competitions for major international tournament are added. "All internationals" include all types of international soccer games of the English national soccer team, including non-tournament 'friendly' matches.

Compared to Ashton et al. the mean returns after losses are considerably less negative or even positive. This effect is also visible for the wins, which become less positive. The results are even positive in games that end in a draw, with the exception of tournament finals. 
Table 4

Binomial Statistics (corrected)

\begin{tabular}{|c|c|c|}
\hline & \multirow[t]{2}{*}{ No. of games played } & $\begin{array}{l}\text { No. of returns after a win/loss which are }>/ \leq \text { the } \\
\text { unconditional mean. (Total no. of wins/losses) }\end{array}$ \\
\hline & & Loss \\
\hline All internationals & 210 & $51(103)$ \\
\hline $\begin{array}{l}\text { Tournament finals and } \\
\text { qualifying games }\end{array}$ & 97 & $13^{*}(20)$ \\
\hline Tournament finals games & 35 & $10^{* *}(14)$ \\
\hline
\end{tabular}

This table presents our corrected binomial statistics of Ashton et al. (2003). Like in table 2 the intuition in column "win" is that the average return for the index after a win is greater than the unconditional mean return. The number in brackets is the number of won games of the English team, the number without brackets is the amount of cases where the average return for the index after a win is greater than the unconditional mean return.

In column "loss" they test whether the average return for the FTSE 100 index after a loss by the national soccer team is significantly less than the unconditional mean return for all types of matches.

In truth the English soccer team has lost 42 games, the FTSE 100 index has fallen by an amount greater than the unconditional mean return on 24 of these occasions.

$*, * *, * * *$ indicates significance at the $10 \%, 5 \%$ and $1 \%$ level, resp. 
Table 5

Sub Samples. Binomial Statistics

\begin{tabular}{|c|c|c|c|}
\hline & \multirow[t]{2}{*}{ No. of games played } & \multicolumn{2}{|c|}{$\begin{array}{l}\begin{array}{l}\text { No. of returns after a win/loss which are }>/ \leq \text { the } \\
\text { unconditional mean. (Total no. of wins/losses) }\end{array} \\
\end{array}$} \\
\hline & & Win & Loss \\
\hline \multicolumn{4}{|l|}{ Sub-Period 1984 - 1993} \\
\hline $\begin{array}{l}\text { Tournament finals and } \\
\text { qualifying games }\end{array}$ & 54 & $13(25)$ & $9^{* * * *}(10)$ \\
\hline Tournament finals games & 18 & $2(5)$ & $8^{* * *}(8)$ \\
\hline \multicolumn{4}{|l|}{ Sub-Period $1994-2002$} \\
\hline $\begin{array}{l}\text { Tournament finals and } \\
\text { qualifying games }\end{array}$ & 43 & $12(23)$ & $4(10)$ \\
\hline Tournament finals games & 17 & $3(8)$ & $2(6)$ \\
\hline
\end{tabular}


Table 6

Descriptive Statistics without extreme values (i.e. highest and lowest return)

\begin{tabular}{|c|c|c|c|c|}
\hline & Number of games & $\begin{array}{l}\text { Mean return after win } \\
\text { (No. of wins) }\end{array}$ & $\begin{array}{l}\text { Mean return after } \\
\text { draw (No. of draws) }\end{array}$ & $\begin{array}{l}\text { Mean return after loss } \\
\text { (No. of losses) }\end{array}$ \\
\hline \multicolumn{5}{|c|}{$\begin{array}{l}\text { The FTSE } 100 \text { index: Period of Investigation } 6 \text { January 1984-3 July } 2002 \\
\text { Unconditional Daily Return on the index } 0.03655 \%\end{array}$} \\
\hline $\begin{array}{l}\text { Tournament finals and } \\
\text { qualifying games }\end{array}$ & 91 & $0.1105(46)$ & $0.0809(27)$ & $-0.1303 \%(18)$ \\
\hline Tournament finals games & 29 & $-0.1258 \%(11)$ & $-0.5402 \%(6)$ & $-0.2286 \%(12)$ \\
\hline
\end{tabular}
one out of six cases the algebraic sign changes. 